\title{
Artesunate induces apoptosis and inhibits growth of Eca109 and Ec9706 human esophageal cancer cell lines in vitro and in vivo
}

\author{
LIANG LIU, LIAN-FU ZUO, JING ZUO and JING WANG \\ Department of FCM Analysis, Tumor Institute, The Fourth Hospital of Hebei Medical University, \\ Shijiazhuang, Hebei 050011, P.R. China
}

Received June 19, 2014; Accepted March 3, 2015

DOI: $10.3892 / \mathrm{mmr} .2015 .3517$

\begin{abstract}
Esophageal cancer is a common malignant tumor worldwide with a high incidence rate in China and it is a great threat to human health. Combined modality therapy is used for chemotherapeutic treatment of esophageal cancer; however, drug resistance and side effects of the drugs is a major barrier to the success of chemotherapy. As chemotherapy with common drugs is far from providing satisfactory clinical outcomes for patients with esophageal cancer, more efficient drugs are urgently required. Artesunate (Art) is the first-line treatment option for malaria; however, it was recently revealed that Art has remarkable anti-tumor activity, making it a novel candidate for cancer chemotherapy. Although the anti-cancer effects of Art have been well documented, its potential against esophageal cancer has rarely been explored. The present study aimed to investigate the significance and mechanism of the anti-proliferative activity of Art on esophageal cancer cells in vitro and in vivo. In the in vitro experiments, Art inhibited the growth as well as induced cell apoptosis and cell cycle arrest of esophageal cancer cell lines (Eca109 and Ec9706) in a concentration-dependent manner. Furthermore, downregulation of mitochondrial membrane potential, B-cell lymphoma-2 (BCL-2) and CDC25A, as well as upregulation of BCL-2-associated X protein (Bax) and caspase-3 expression in Art-treated cells were identified. In addition, an in vivo study showed that Art produced a dose-dependent tumor regression in nude mice, while side effects were low. The anti-tumor activity of $200 \mathrm{mg} / \mathrm{kg}$ Art was similar to that of $3 \mathrm{mg} / \mathrm{kg}$ cisplatin. In conclusion, Art exerted concentration-dependent inhibitory activity against esophageal cancer in vivo and in vitro by inducing cell apoptosis and cell cycle arrest through affecting mitochondrial membrane potential, BCL-2, Bax, caspase- 3 and CDC25A.
\end{abstract}

Correspondence to: Dr Liang Liu, Department of FCM Analysis, Tumor Institute, The Fourth Hospital of Hebei Medical University, 12 Jiankang Road, Shijiazhuang, Hebei 050011, P.R. China E-mail: aliangdaziran@163.com

Key words: artesunate, cell division cycle 25 A, mitochondrial membrane potential, esophageal carcinoma, flow cytometry

\section{Introduction}

Artesunate (Art), a water-soluble hemisuccinate derivative of dihydroartemisinin, is the most widely used member of the family of artemisinin drugs. Artemisinin compounds are in widespread use for the treatment of severe and complicated malaria in humans. Art has been the most commonly used derivative for $>15$ years, and according to a large number of clinicians, intravenous administration of Art is the most effective treatment for severe malaria (1-3). The effectiveness of Art in vivo has been attributed to its rapid and extensive conversion to dihydroartemisinin (DHA) (4). Studies have reported that Art may have anti-cancer effects, as Art inhibited the growth of cancer cells via cell cycle arrest and induction of apoptosis $(5,6)$.

Deregulated cell cycle progression is a hallmark of cancer. Regulatory components of the cell cycle machinery often become targets of genetic alterations during carcinogenesis. Cyclin-dependent kinases (CDK) have central roles in promoting cell cycle progression and uncontrolled activation of CDKs is the driving force of cancer cell proliferation (7). Overexpression of CDKs and cyclins, as well as downregulation of CDK inhibitors, is found in the majority of human cancers, and components of the CDK system appear to be functionally redundant. CDC25 genes are cell cycle-activating phosphatases that remove the inhibitory phosphates of threonine and tyrosine residues at the ATP-binding sites of CDK $(8,9)$. CDC25A is member of the CDC25 gene family. CDC25A regulates G1/S- and G2/M-associated CDK activities $(10,11)$. In late $\mathrm{G} 1, \mathrm{~S}$ and $\mathrm{G} 2$ phase, CDC25A protein has a short half-life as a consequence of checkpoint kinase 1 (CHK1)-mediated phosphorylation during a normal cell cycle. DNA damage or inhibition of DNA replication activates CHK1 and CHK2 kinases that then lead to rapid degradation of CDC25A, thereby preventing cell cycle progression $(12,13)$. Furthermore, concordant in vitro and in vivo findings showed that CDC25A is overexpressed in various types of human neoplastic malignancy (14-17).

Cell apoptosis and cell growth are regulated through complex signaling systems in the human body, and their disorder or imbalance may induce the development of tumors. The efficiency of chemotherapy drugs is often evaluated by their ability to induce cell apoptosis. Mitochondrial membrane potential, B-cell lymphoma-2 (BCL-2), BCL-2-associated X 
protein (Bax) and caspase-3 regulate cell apoptosis, where upregulation of bax and caspase-3, and downregulation of mitochondrial membrane potential and bcl-2 may result in cell apoptosis $(18,19)$.

In the present study, the anti-cancer activity of Art was examined by assessing its effect on the expression of CDC25A, mitochondrial membrane potential, BCL-2, Bax and caspase-3 in Eca109 and Ec9706 human esophageal carcinoma cells as well as in a nude mouse xenograft model.

\section{Materials and methods}

Chemicals and reagents. Art was purchased from Guiling Pharmaceutical Co. (Guangxi, China). RT-PCR kit was obtained from Promega Corporation (Madison, WI, USA). Mouse anti-human CDC25A (cat. no. sc-7389), BCL-2 (cat. no. sc-7382), Bax (cat. no. sc-20067) and Caspase-3 (cat. no. sc-7272) monoclonal antibodies were purchased from Santa Cruz Biotechnology, Inc. (Santa Cruz, CA, USA). TRIzol was obtained from Bio Basic Inc. (Markham, ON, Canada).

Cells and cell culture. The human esophageal cancer cell line Eca109 was obtained from the Cancer Institute of the Fourth Hospital of Hebei Medical University (Shijiazhuang, China). Human esophageal cancer cells Ec9706 were obtained from the Molecular Oncology State Key Laboratory, Cancer Institute and Hospital, Chinese Academy of Medical Sciences (Beijing, China).

Cells were cultured in RPMI 1640 medium (Sigma-Aldrich, St. Louis, MO, USA) supplemented with $10 \%$ fetal bovine serum (Sigma-Aldrich), 100 units/ml penicillin (North China Pharmaceutical Co., Ltd., Shijiazhuang, China) and $100 \mu \mathrm{g} / \mathrm{ml}$ streptomycin (North China Pharmaceutical Co., Ltd., Shijiazhuang, China) at $37^{\circ} \mathrm{C}$ in a humidified atmosphere of $5 \% \mathrm{CO}_{2}$.

Animals. BALB/c nu/nu mice were purchased from The Institute of Laboratory Animal Science, Chinese Academy of Medical Sciences (Beijijng, China). The mice were maintained under specific pathogen-free conditions at room temperature $\left(23 \pm 1^{\circ} \mathrm{C}\right)$ and relative humidity (40-60\%), and were supplied with sterilized food and water. The animals were maintained in $12 \mathrm{~h}$ light/dark cycles and were provided access to food and water ad libitum. Animal experiments were conducted according to the Institutional Animal Care and Use Committee guidelines, and were approved by the ethics committee of the Fourth Hospital of Hebei Medical University (Shijiazhuang, China). 4-6 week-old female/male nu/nu mice weighing 18-20 g were inoculated with $200 \mu 1$ Eca109 cells (6x10 6 cells) in the left forelimb. This model has been used for more than two decades to study the efficacy of chemotherapeutic drugs against cancer. A total of 24 inoculated Eca109-transplanted tumor mice were divided into four groups: The negative control group was intraperitoneally injected physiological saline, and treatment groups were injected with $100 \mathrm{mg} / \mathrm{kg}$ Art, $200 \mathrm{mg} / \mathrm{kg}$ Art or $3 \mathrm{mg} / \mathrm{kg}$ cisplatin. The mice were treated once a day for 14 days. Following 14 days of treatment, the mice were sacrified by cervical dislocation and tumor volume was measured at the shortest and the longest diameters of the tumor using a vernier caliper. The tumor volume was calculated using the following standard formula: $\mathrm{axb}^{2} / 2$, where $\mathrm{a}$ is the longest diameter and $\mathrm{b}$ is the shortest diameter.

\section{Flow cytometric analysis}

Analysis of cell apoptosis. Cultured tumor cells (Eca109 and Ec9706 cells) treated with various concentrations of Art ( 0 , 30,60 or $120 \mu \mathrm{mol} / \mathrm{l}$ ) for $24 \mathrm{~h}$ were harvested using pancreatin (Sigma-Aldrich). The cells were stained with propidium iodide (PI; Sigma-Aldrich) and annexin V-fluorescein isothiocyanate (FITC; Beckman Coulter, Miami, FL, USA), and analyzed using a Beckman Coulter Epics-XL type flow cytometer (Beckman Coulter). Early apoptotic cells were positive for annexin $\mathrm{V}$ and negative for PI staining, whereas late apoptotic cells undergoing secondary necrosis were positive for annexin $\mathrm{V}$ and PI staining.

Cell cycle analysis. Cultured tumor cells (Eca109 and Ec9706 cells; $1 \times 10^{6}$ cells) were harvested routinely following treatment with various concentrations of Art $(0,30,60$ or $120 \mu \mathrm{mol} / \mathrm{l})$ for $24 \mathrm{~h}$. Cells were fixed in $70 \%(\mathrm{w} / \mathrm{v})$ ice-cold ethanol (Zeneca Co., Ltd., Handan, China). Following two washes with ice-cold phosphate-buffered saline (PBS; Sigma-Aldrich), the fixed cells were stained with $1 \mathrm{ml}$ PI solution $(50 \mu \mathrm{g} / \mathrm{ml})$. Following incubation for $30 \mathrm{~min}$ in the dark at $4^{\circ} \mathrm{C}$ and two washes with ice-cold PBS, the stained cells were re-suspended in $1 \mathrm{ml}$ PBS. The stained cells were analyzed using a Beckman Coulter Epics-XL type flow cytometer (Beckman Coulter).

Analysis of CDC25A, BCL-2, Bax and caspase-3 protein. Cultured tumor cells (Eca109 and Ec9706 cells) were harvested routinely following treatment with various concentrations of Art $(0,30,60$ or $120 \mu \mathrm{mol} / \mathrm{l})$ for $24 \mathrm{~h}$. Cells were fixed overnight with $70 \%$ ice-cold ethanol. Following two washes with ice-cold PBS, the fixed cells were re-suspended in $1 \mathrm{ml}$ PBS containing CDC25A, BCL-2, Bax and caspase-3 antibody (1:100), respectively, following incubation for $30 \mathrm{~min}$ in the dark at room temperature. Following two washes with PBS, cells were re-suspended in $1 \mathrm{ml}$ PBS containing antibody II (immunoglobulin G-FITC; Jackson ImmunoResearch Laboratories, Inc., West Grove, PA, USA) with incubation for $30 \mathrm{~min}$ in the dark at room temperature. Following two washes with PBS, cells were re-suspended in $1 \mathrm{ml}$ PBS. The stained cells were analyzed using a Beckman Coulter Epics-XL type flow cytometer (Beckman Coulter).

Analysis of mitochondrial membrane potential in Eca109 and Ec9706 cells. Cultured tumor cells (Eca109 and Ec9706 cells) were harvested routinely following treatment with various concentrations of Art $(0,30,60$ or $120 \mu \mathrm{mol} / \mathrm{l})$ for $24 \mathrm{~h}$. Following two washes with ice-cold PBS, the cells were stained using $1 \mathrm{ml}$ rhodamine 123 solution ( $10 \mu \mathrm{g} / \mathrm{ml}$; Sigma-Aldrich). Following incubation for $30 \mathrm{~min}$ in the dark at $37^{\circ} \mathrm{C}$ and two washes with ice-cold PBS, the stained cells were re-suspended in $1 \mathrm{ml}$ PBS. The stained cells were analyzed using a Beckman Coulter Epics-XL type flow cytometer (Beckman Coulter).

Statistical analysis. Values are expressed as the mean \pm standard deviation and were statistically analyzed using multiple analysis of variance followed by the Newman-Keuls method of post-hoc comparison (SPSS software; SPSS, Inc., Chicago, IL, USA). $\mathrm{P}<0.05$ was considered to indicate a significant difference. 

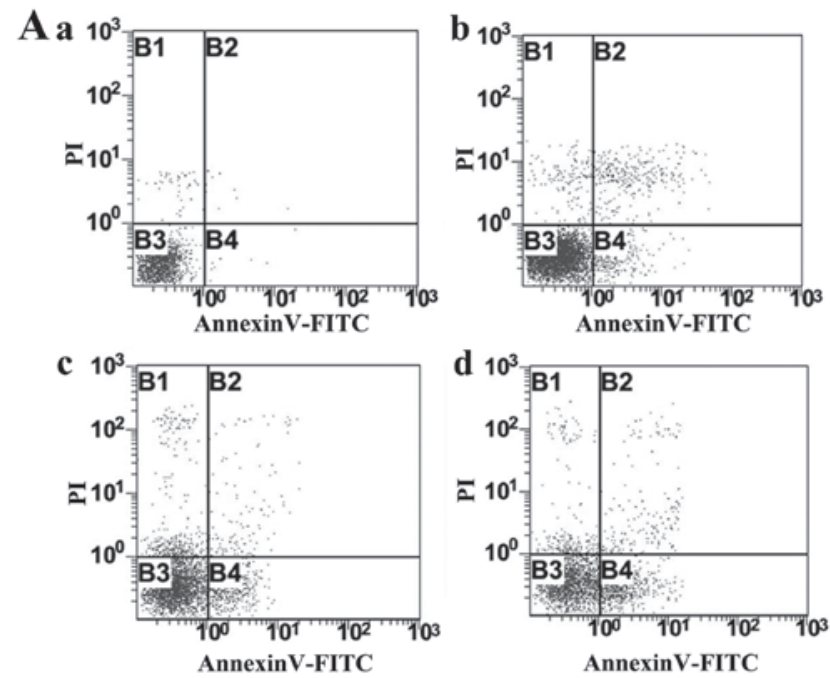

B

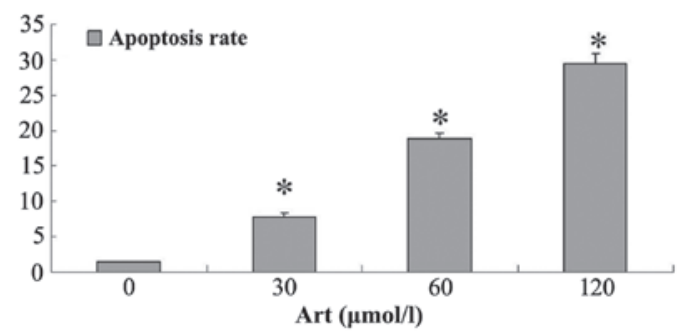

Figure 1. Eca109 cell apoptosis following treatment with various concentrations of Art. (A) Apoptosis rare of Eca109 cells following treatment with Art was assessed using flow cytometry. (B) Eca109 cell apoptosis rate following treatment with Art $(30,60$ or $120 \mu \mathrm{mol} / 1)$ was significantly higher than that in the control group $\left({ }^{*} \mathrm{P}<0.01\right)$. The percentage of apoptotic Eca109 cells increased with increasing Art concentration. Data are presented as the mean \pm standard deviation ( $\mathrm{n}=6$ ). (a) Control group, (b) $30 \mu \mathrm{mol} / 1$ Art group, (c) $60 \mu \mathrm{mol} / 1$ Art group and (d) $120 \mu \mathrm{mol} / 1$ Art group. Art, artesunate; FITC, fluorescein isothiocyanate; PI, propidium iodide.

\section{Results}

Art induces apoptosis and cell cycle arrest in human esophageal cancer cells. Following Art exposure, Eca109 and Ec9706 cells underwent apoptosis and cell cycle arrest in a dose-dependent manner. In the range of 30-120 $\mu \mathrm{mol} / 1$, Art induced apoptosis, as determined by Annexin V/PI staining (Figs. 1 and 2). The percentages of apoptotic Eca109 and Ec9706 cells increased with increasing Art concentration (Figs. 1 and 2). Treatment of Eca109 and Ec9706 cells with Art resulted in pronounced G0/1 phase arrest in a dose-dependent manner (Figs. 3 and 4). The results for Ec9706 cells were consistent with those for Eca109 cells.

Effects of Art on CDC25A, BCL-2, Bax and caspase-3 expression levels in Eca109 and Ec9706 cells. Eca109 and Ec9706 cells were treated with $0,30,60$ and $120 \mu \mathrm{mol} / 1$ Art for $24 \mathrm{~h}$, washed with cold PBS, and analyzed for protein expression of CDC25A, BCL-2, Bax and caspase-3 using flow cytometry. The protein expression of CDC25A and BCL-2 was significantly downregulated compared with that of the controls $(\mathrm{P}<0.05)$ when the Eca109 and Ec9706 cells were treated for $24 \mathrm{~h}$ with various concentrations of Art (30-120 $\mu \mathrm{mol} / \mathrm{l})$ (Figs. 5-8). By contrast, the Bax and caspase-3 protein expression was significantly upregulated compared with that in
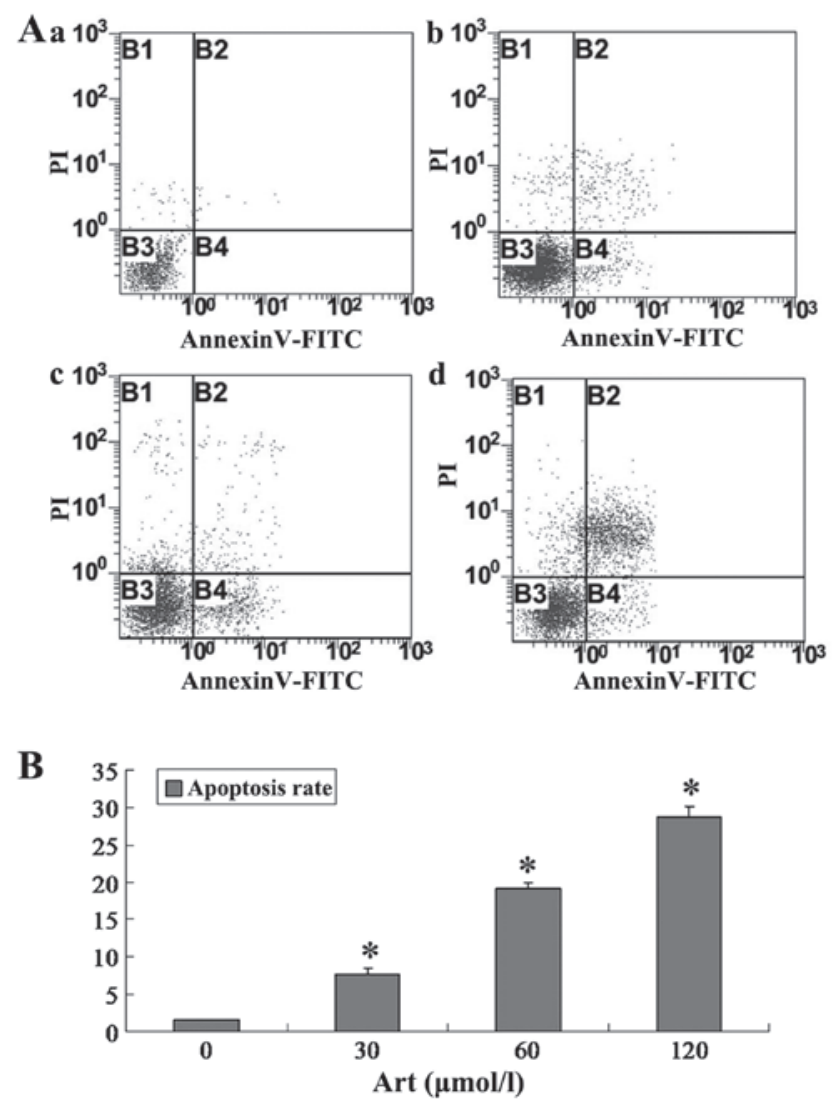

Figure 2. Ec9706 cell apoptosis following treatment with various concentrations of Art. (A) Apoptosis rare of Ec9706 cells following treatment with Art was assessed using flow cytometry. (B) Ec9706 cell apoptosis rate following treatment with Art $(30,60$ or $120 \mu \mathrm{mol} / 1)$ was significantly higher than that of the control group $\left({ }^{*} \mathrm{P}<0.01\right)$. The percentage of apoptotic Ec9706 cells increased with increasing Art concentrations. Data are presented as the mean \pm standard deviation ( $\mathrm{n}=6$ ). (a) Control group, (b) $30 \mu \mathrm{mol} / 1$ Art group, (c) $60 \mu \mathrm{mol} / 1$ Art group and (d) $120 \mu \mathrm{mol} / 1$ Art group. Art, artesunate; FITC, fluorescein isothiocyanate; PI, propidium iodide.

the control cells $(\mathrm{P}<0.05)$ following treatment with various concentrations of Art for $24 \mathrm{~h}$ (Figs. 9-12).

Effect of Art on the mitochondrial membrane potential in Eca109 and Ec9706 cells. Eca109 and Ec9706 cells were treated with 0, 30, 60 and $120 \mu \mathrm{mol} / 1$ Art for $24 \mathrm{~h}$, washed with cold PBS and analyzed for the mitochondrial membrane potential using flow cytometry. The mitochondrial membrane potential in the Art group was significantly lower than that in the control group $(\mathrm{P}<0.01)$. The mitochondrial membrane potential in the $120 \mu \mathrm{mol} / \mathrm{ml}$ Art group was significantly lower than that in the $30 \mu \mathrm{mol} / \mathrm{ml}$ and $60 \mu \mathrm{mol} / \mathrm{ml}$ Art group $(\mathrm{P}<0.01)$ (Figs. 13 and 14).

Inhibitory effect of Art on the growth of xenograft tumors. On the basis of the in vitro results, the present study examined the effects of Art on the growth of Eca109 cells in mouse xenograft models. An Eca109-transplanted tumor nude mouse model was established successfully. As shown in Fig. 15, Art inhibited the growth of Eca109-transplanted tumors in nude mice. The volume and weight of transplanted tumors in the Art and cisplatin groups were lower than those in the normal saline-injected control group $(\mathrm{P}<0.05)$. 

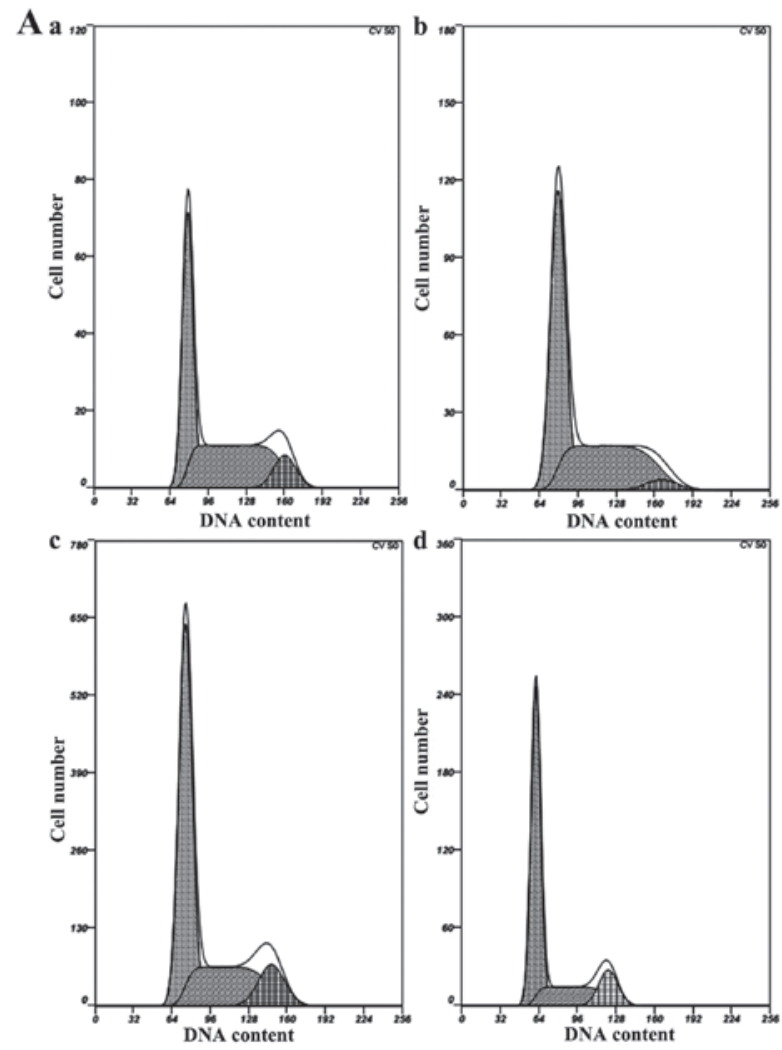

B

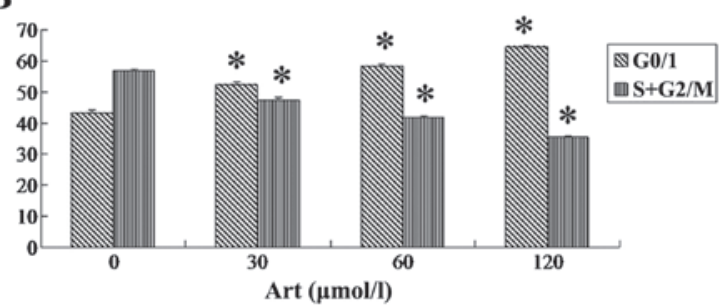

Figure 3. Eca109 cell cycle following treatment with various concentrations of Art. (A) Cell cycle of Eca109 cells following treatment with Art as detected by flow cytometry. (B) The percentage of Eca109 cells in G0/1 phase following treatment with Art $(30,60$ or $120 \mu \mathrm{mol} / \mathrm{l})$ was significantly higher than that in the control group ( $\mathrm{P}<0.01)$. Treatment of Eca109 cells with Art resulted in pronounced G0/1 arrest in a dose-dependent manner. Data are presented as the mean \pm standard deviation ( $\mathrm{n}=6$ ). (a) Control group, (b) $30 \mu \mathrm{mol} / 1$ Art group, (c) $60 \mu \mathrm{mol} / 1$ Art group and (d) $120 \mu \mathrm{mol} / 1$ Art group. Art, artesunate.

\section{Discussion}

Cancer therapy is often based on surgery, chemotherapy and radiation therapy. Chemotherapy is one of the main therapies for the majority of cancers, particularly for those with a proneness to invade adjacent tissues and to metastasize to other organs. The effectiveness of chemotherapy is often limited by toxicity to other normal tissues in the body, thereby resulting in chemotherapy failure. Esophageal carcinoma is one of the most common malignant gastrointestinal tumors (20). The incidence of esophageal carcinoma is high in China and it is a great threat to human health. As chemotherapy with normal anti-cancer drugs is far from providing satisfactory clinical outcomes for patients with esophageal cancer, more efficient drugs and drug combinations are urgently required. Artemisins are a class of compounds that are first-line treatment options for
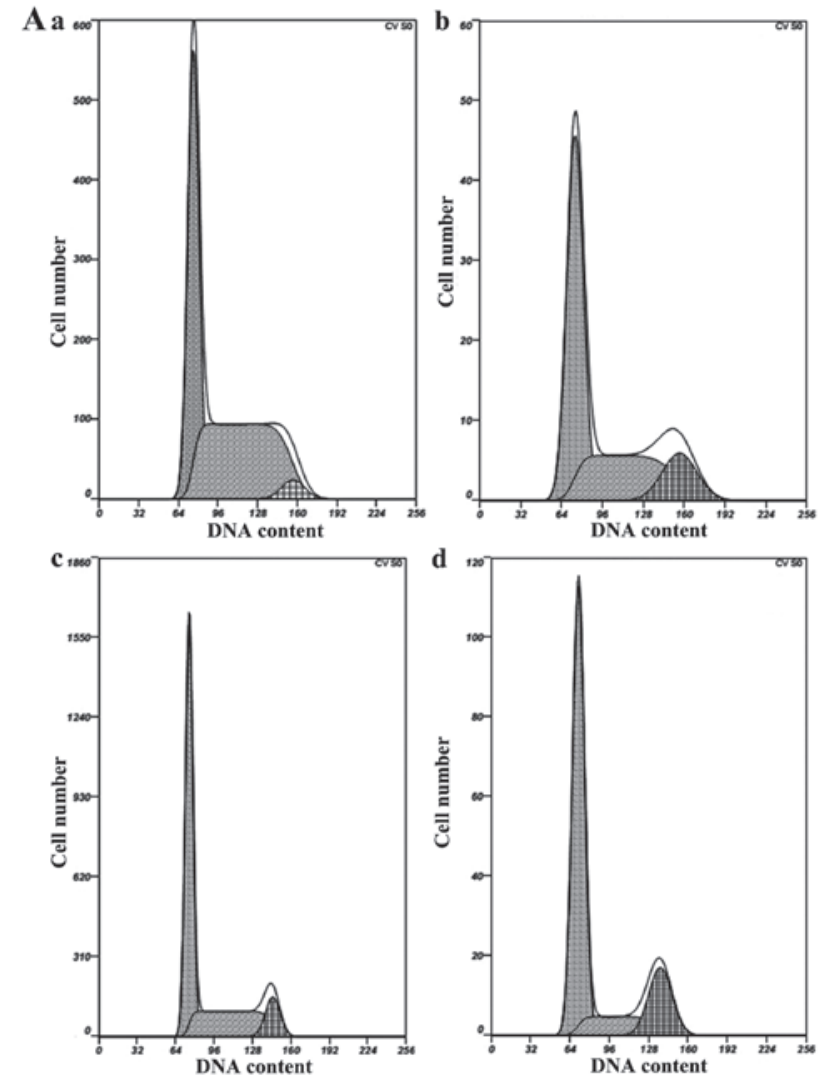

B

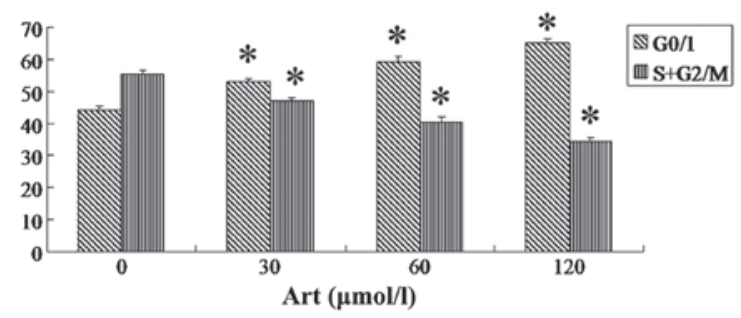

Figure 4. Ec9706 cell cycle following treatment with various concentrations of Art. (A) Cell cycle of Ec9706 cells following treatment with Art as detected by flow cytometry. (B) The population of Ec9706 cells in G0/1 phase following treatment with Art $(30,60$ or $120 \mu \mathrm{mol} / \mathrm{l})$ was significantly higher than that in the control group $\left({ }^{*} \mathrm{P}<0.01\right)$. Treatment of Ec9706 cells with Art resulted in pronounced G0/1 arrest in a dose-dependent manner. Data are presented as the mean \pm standard deviation ( $\mathrm{n}=6$ ). (a) Control group, (b) $30 \mu \mathrm{mol} / 1$ Art group, (c) $60 \mu \mathrm{mol} / 1$ Art group and (d) $120 \mu \mathrm{mol} / 1 \mathrm{Art}$ group. Art, artesunate.

malaria $(21,22)$, and its water-soluble derivative, Art is a remarkable anti-malarial agent, particularly in severe and drug-resistant cases $(23,24)$. Recently, Art has also been demonstrated to exert profound anti-cancer activity (25). Efferth et al (5) reported a profound cytotoxic action of Art against cancer cell lines of different tumor types. However, a detailed understanding of the molecular mechanisms during Art-induced cell death in cancer cells is limited. The present study reported that Art exerted potent cytotoxic effects on the human esophageal cancer Eca109 and Ec9706 cell lines in vitro and in vivo. The cytotoxicity of Art was mediated by apoptosis and cell cycle arrest, which was supported by assessment of apoptosis, cell cycle analysis and determination of expression levels of apoptosis- and cell cycle-associated proteins. Apoptosis has important roles in maintaining cell homeostasis and dysfunction of apoptotic signalling may cause serious conditions such as cancer. 

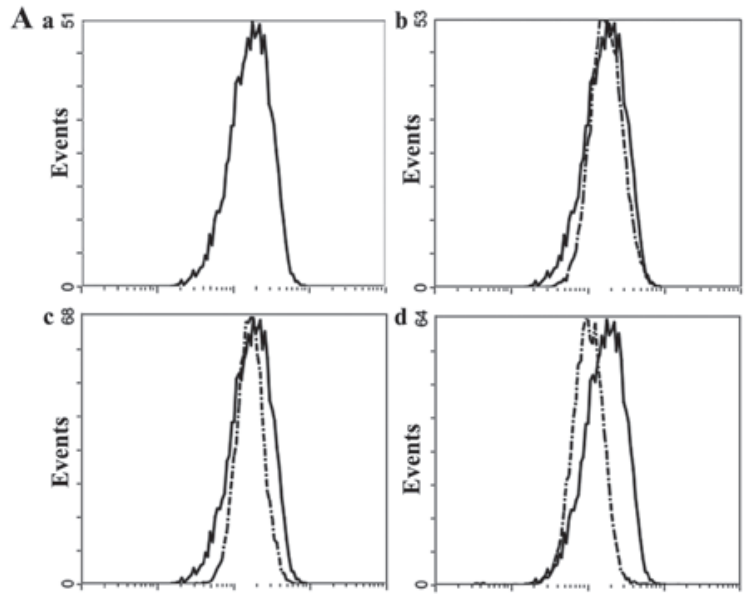

B

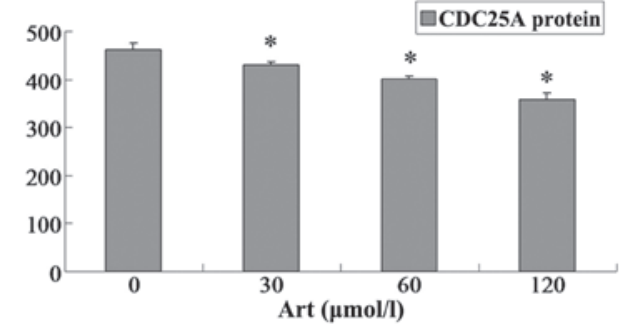

Figure 5. CDC25A protein expression of Eca109 cells following treatment with Art. (A) CDC25A protein expression detected by flow cytometry. (B) CDC25A protein expression levels in the Art group were significantly lower than those in the control group $\left({ }^{*} \mathrm{P}<0.05\right)$. Data are presented as the mean \pm standard deviation ( $\mathrm{n}=6$ ). (a) Control group, (b) $30 \mu \mathrm{mol} / 1$ Art group, (c) $60 \mu \mathrm{mol} / 1$ Art group and (d) $120 \mu \mathrm{mol} / 1$ Art group. Art, artesunate.
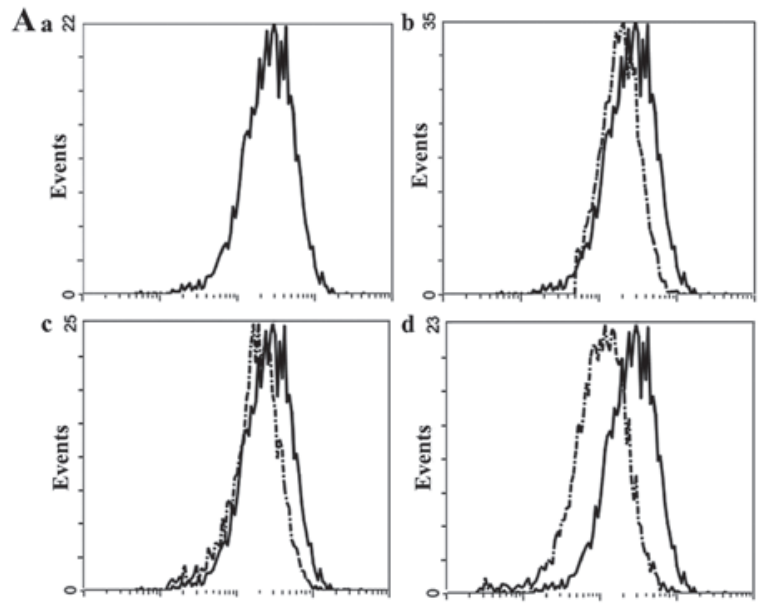

B

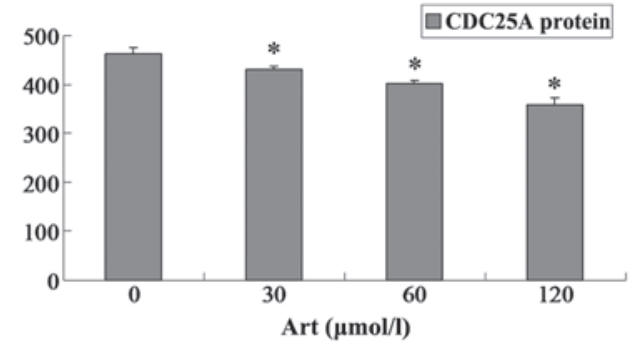

Figure 6. CDC25A protein expression of Ec9706 cells following treatment with Art. (A) CDC25A protein expression of Ec9706 cells was detected by flow cytometry. (B) CDC25A protein expression levels in the Art group were significantly lower than those in the control group $\left({ }^{*} \mathrm{P}<0.05\right)$. Data are presented as the mean \pm standard deviation $(\mathrm{n}=6)$. (a) Control group, (b) $30 \mu \mathrm{mol} / 1$ Art group, (c) $60 \mu \mathrm{mol} / 1$ Art group and (d) $120 \mu \mathrm{mol} / 1 \mathrm{Art}$ group. Art, artesunate.
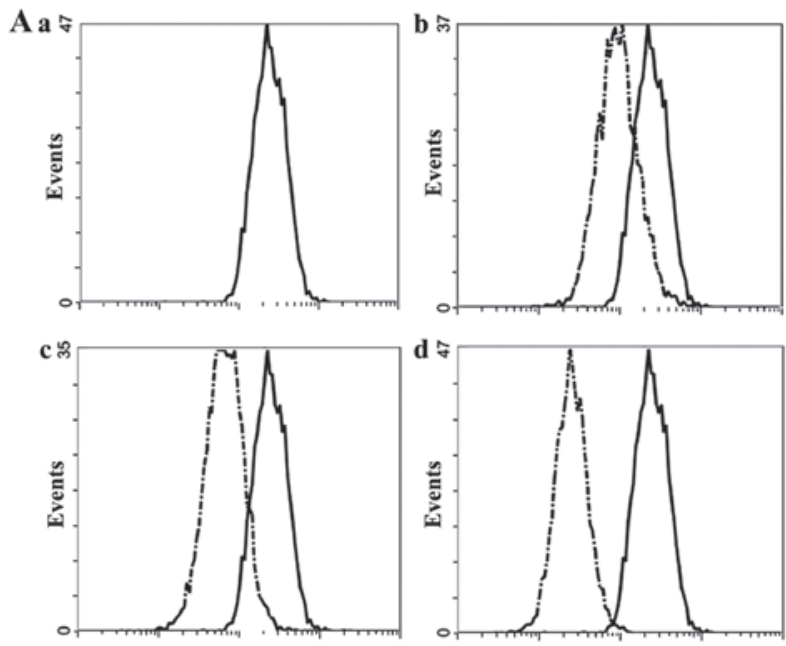

B

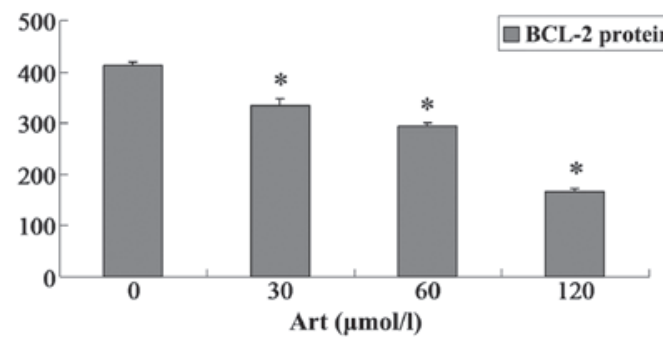

Figure 7. BCL-2 protein expression in Eca109 cells following treatment with Art. (A) BCL-2 protein expression detected by flow cytometry. (B) BCL-2 protein expression levels in the Art-treated group were significantly lower than those in control group $\left({ }^{*} \mathrm{P}<0.01\right)$. Data are presented as the mean \pm standard deviation (n=6). (a) Control, (b) $30 \mu \mathrm{mol} / 1 \mathrm{Art}$, (c) $60 \mu \mathrm{mol} / 1$ Art and (d) $120 \mu \mathrm{mol} / 1$ Art. Art, artesunate; BCL, B-cell lymphoma.
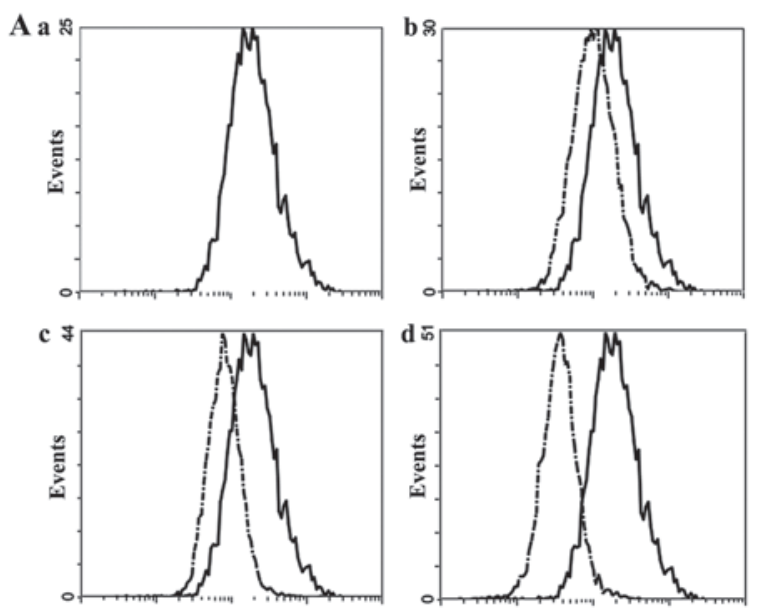

B

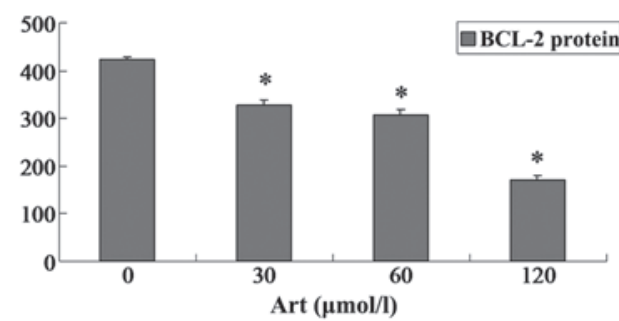

Figure 8. BCL-2 protein expression in Ec9706 cells following treatment with Art. (A) BCL-2 protein expression detected by flow cytometry. (B) BCL-2 protein expression levels in the Art group were significantly lower than those in the control group $\left({ }^{*} \mathrm{P}<0.01\right)$. Data are presented as the mean \pm standard deviation (n=6). (a) Control, (b) $30 \mu \mathrm{mol} / 1 \mathrm{Art}$, (c) $60 \mu \mathrm{mol} / 1$ Art and (d) $120 \mu \mathrm{mol} / 1 \mathrm{Art}$. Art, artesunate; BCL, B-cell lymphoma. 


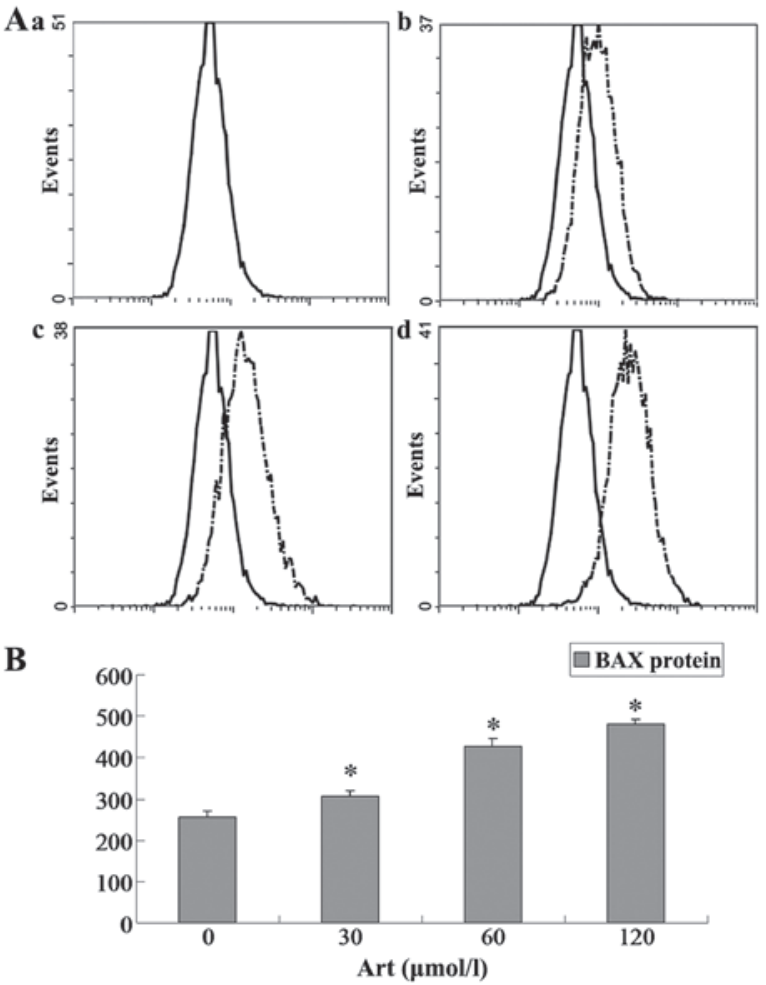

Figure 9. BAX protein expression in Eca109 cells following treatment with Art. (A) BAX protein expression detected by flow cytometry. (B) BAX protein expression levels in the Art group were significantly higher than those in the control group ( $\mathrm{P}<0.01)$. Data are presented as the mean \pm standard deviation (n=6). (a) Control, (b) $30 \mu \mathrm{mol} / 1 \mathrm{Art}$, (c) $60 \mu \mathrm{mol} / 1 \mathrm{Art}$ and (d) $120 \mu \mathrm{mol} / 1 \mathrm{Art}$. Art, artesunate; BAX, B-cell lymphoma-associated X.



Figure 10. BAX protein expression in Ec9706 cells following treatment with Art. (A) BAX protein expression detected by flow cytometry. (B) BAX protein expression levels in the Art group were significantly higher than those in the control group ( $(\mathrm{P}<0.01)$. Data are presented as the mean \pm standard deviation (n=6).(a) Control, (b) $30 \mu \mathrm{mol} / 1$ Art, (c) $60 \mu \mathrm{mol} / 1$ Art and (d) $120 \mu \mathrm{mol} / 1$ Art. Art, artesunate; BAX, B-cell lymphoma-associated X.
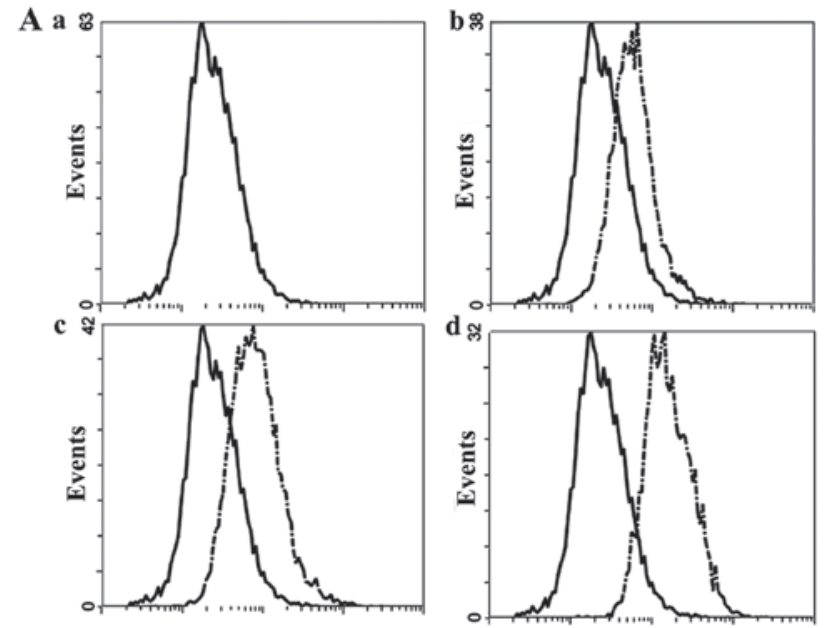

B

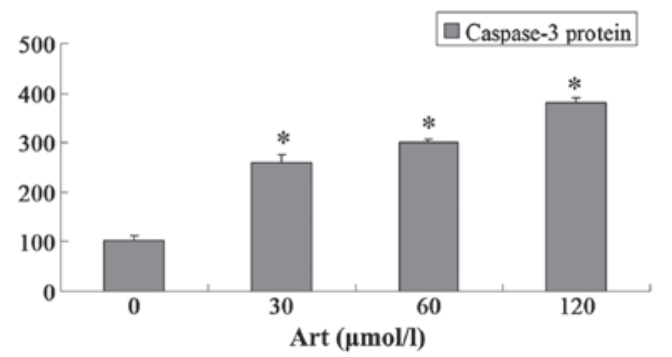

Figure 11. Caspase-3 protein expression in Eca109 cells following treatment with Art. (A) Caspase-3 protein expression detected by flow cytometry. (B) Caspase-3 protein expression levels in the Art group were significantly higher than those in the control group $\left({ }^{*} \mathrm{P}<0.01\right)$. Data are presented as the mean \pm standard deviation (n=6). (a) Control, (b) $30 \mu \mathrm{mol} / 1$ Art, (c) $60 \mu \mathrm{mol} / 1$ Art and (d) $120 \mu \mathrm{mol} / 1$ Art. Art, artesunate.
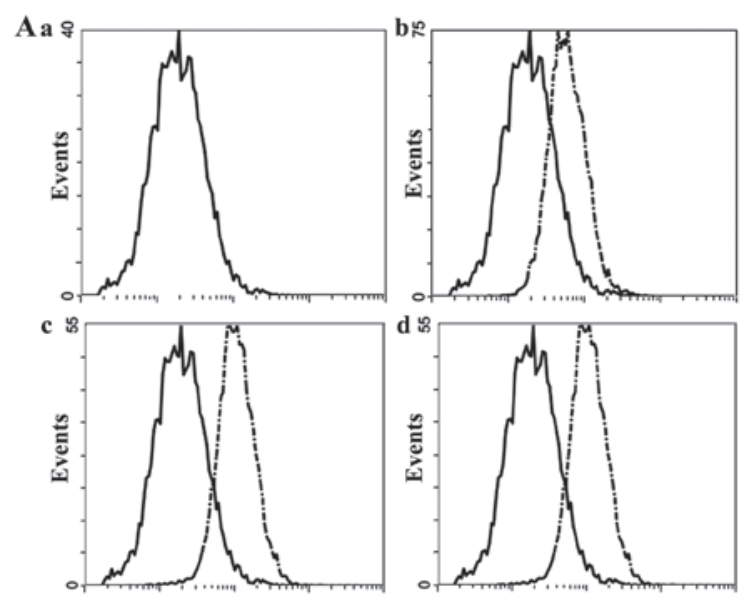

B

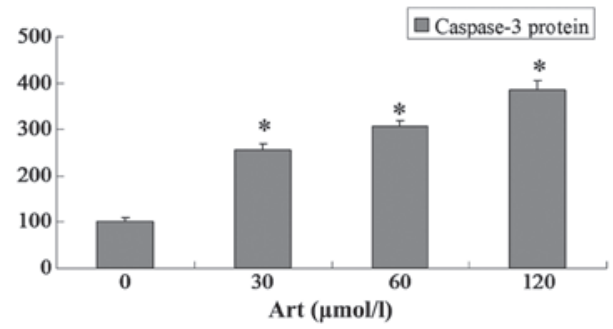

Figure 12. Caspase-3 protein expression in Ec9706 cells following treatment with Art. (A) Caspase-3 protein expression detected by flow cytometry. (B) Caspase-3 protein expression levels in the Art group were significantly higher than those in the control group $\left({ }^{*} \mathrm{P}<0.01\right)$. Data are presented as the mean \pm standard deviation (n=6). (a) Control, (b) $30 \mu \mathrm{mol} / 1 \mathrm{Art}$, (c) $60 \mu \mathrm{mol} / 1$ Art and (d) $120 \mu \mathrm{mol} / 1$ Art. Art, artesunate. 

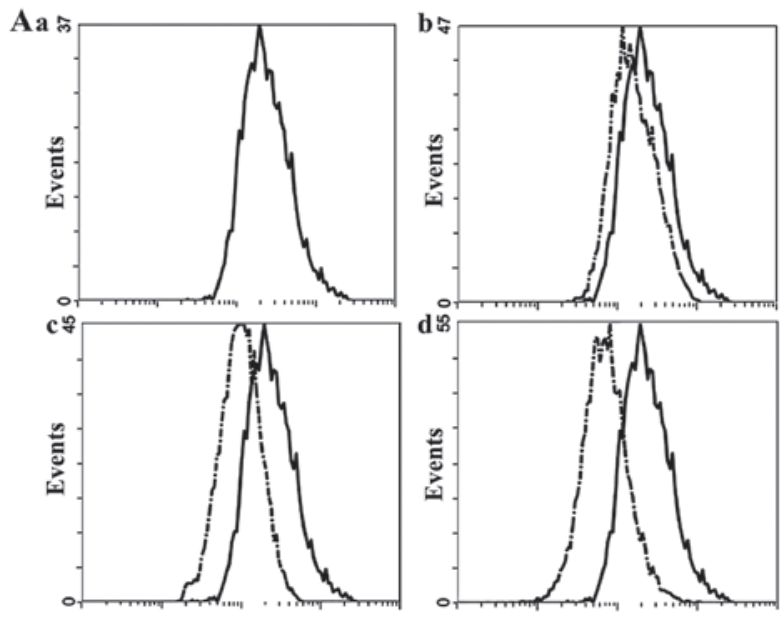

B

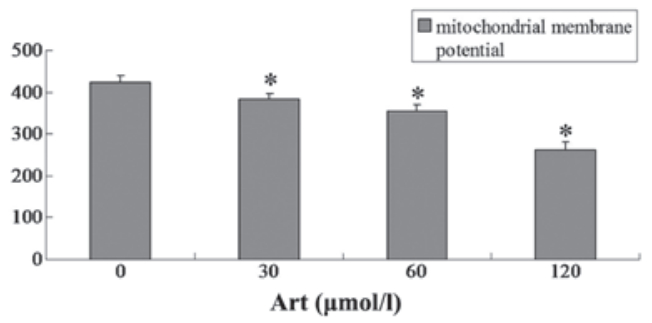

Figure 13. Mitochondrial membrane potential of Eca109 cells following treatment with Art. (A) Mitochondrial membrane potential detected by flow cytometry. (B) The mitochondrial membrane potential in the Art group was significantly lower than that in the control group ( $(\mathrm{P}<0.01)$. Data are presented as the mean \pm standard deviation $(\mathrm{n}=6)$. (a) Control group, (b) $30 \mu \mathrm{mol} / 1$ Art group, (c) $60 \mu \mathrm{mol} / 1$ Art group and (d) $120 \mu \mathrm{mol} / 1 \mathrm{Art}$ group. Art, artesunate.

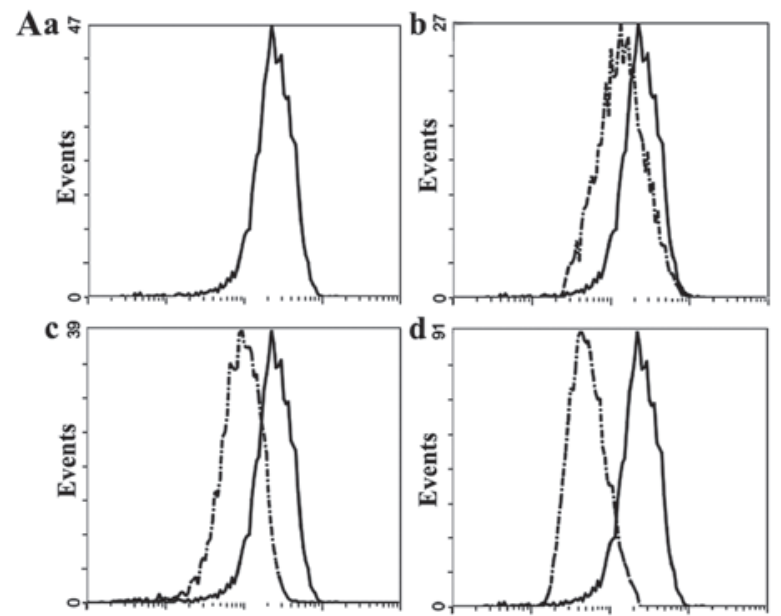

B

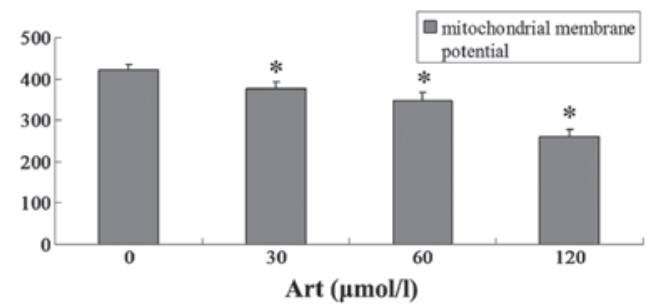

Figure 14. Mitochondrial membrane potential of Ec9706 cells following treatment with Art. (A) Mitochondrial membrane potential detected by flow cytometry. (B) The mitochondrial membrane potential in the Art group was significantly lower than that in the control group $\left({ }^{*} \mathrm{P}<0.01\right)$. Data are presented as the mean \pm standard deviation (n=6). (a) Control group, (b) $30 \mu \mathrm{mol} / 1 \mathrm{Art}$ group, (c) $60 \mu \mathrm{mol} / 1$ Art group and (d) $120 \mu \mathrm{mol} / 1$ Art group. Art, artesunate.

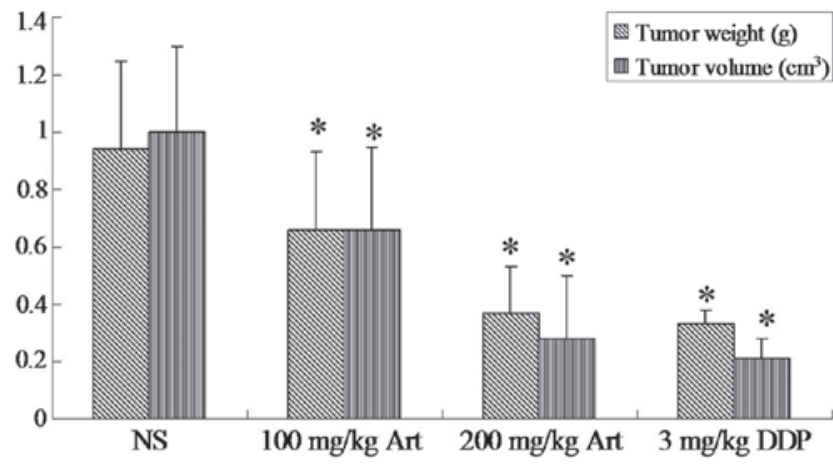

Figure 15. Inhibitory effect of Art on the growth of nude mice xenograft tumors. The volume and weight of transplanted tumors in the Art group and DPP group were lower than those in the NS control group $\left({ }^{*} \mathrm{P}<0.05\right)$. Data are presented as the mean \pm standard deviation $(n=6)$. Art, artesunate; DPP, cisplatin; NS, normal saline-treated group.

At present, apoptosis has been the most studied mechanism in anti-cancer therapy $(26,27)$. Cell apoptosis is a programmed and gene-controlled cell death and involves complex regulatory mechanisms. Loss of the mitochondrial transmembrane potential is an indicator and inducer of apoptosis (26). In the present study, the apoptosis-inducing effect of Art on Eca109 and Ec9706 cells through the mitochondrial pathway was studied in vitro. Treatment with Art induced apoptosis in Eca109 and Ec9706 cells in a dose-dependent manner, which was detected by annexin V/PI staining. In addition, the in-vivo study showed that Art exerted a significant growth inhibitory effect on xenograft tumors in nude mice. Hamacher-Brady et al (6) showed that Art was able to induce mitochondrial apoptosis in the breast cancer cell line MCF-7, which was consistent with the results of the present study. On the other hand, it has been reported that the anti-tumor mechanism of Art was not caused by apoptosis. Zhou et al (28) showed that Art suppressed the proliferation of gastric cancer via oncosis rather than apoptosis. The results of the present study demonstrated that in esophageal cancer cells, Art exerted multifarious effects on proteins involved in apoptosis signaling. Downstream of BCL-2 protein expression and upstream of Bax protein expression, mitochondrial apoptotic cell death was activated. The BCL-2 and Bax proteins are members of the BCL-2 family, which consists of pro-apoptotic and anti-apoptotic proteins that exert opposing effects on mitochondria (29). Increased expression of the anti-apoptotic protein BCL-2 is involved in the development and progression of numerous tumor types. BCL-2 localizes to cellular membranes, particularly in mitochondria, where it stabilizes the transmembrane potential and reduces membrane permeability. BCL-2 appears to contribute to tumor cell survival by enhancing the rate of cell proliferation and by allowing tumor cells to escape destruction by effector cells of the immune system, whereas Bax can promote the release of cytochrome $\mathrm{C}$ from mitochondria into the cytosol to enhance apoptosis. In the present study, it was found that the BCL-2 protein expression of esophageal cancer cells was downregulated following treatment with various concentrations of Art in a dose-dependent manner, whereas Bax protein expression was upregulated. Furthermore, the mitochondrial membrane potential of esophageal cancer cells was downregulated by Art in a dose-dependent manner. Furthermore, caspase- 3 protein 
expression levels were upregulated following treatment with Art in a dose-dependent manner. In the present study, Art induced esophageal cancer cell apoptosis by modulating the BCL-2 and Bax expression levels, downregulating the mitochondrial membrane potential and upregulating caspase-3 expression levels. At the same time, it was found that Art caused G0/G1 phase arrest of esophageal cancer cells. The cell-cycle protein CDC25A activates CDK2, promoting entry into S-phase of the cell cycle $(30,31)$. Overexpression of CDC25A, which has been previously shown to have oncogenic potential (32), eliminates this checkpoint. According to the results of the present study, Art reduced CDC25A expression in esophageal cancer cells in a dose-dependent manner in vivo and in vitro. The results of the present study revealed that CDC25A was a molecular target of Art, which suggested that the Art may impair G1/S transition, thereby contributing to the prevention of uncontrolled cell growth.

In conclusion, the present study revealed that Art inhibited the growth of esophageal cancer cells by inducing apoptosis and cell cycle arrest. Art is a clinically approved drug for the treatment of malaria and showed low side effects in nude mice. Future studies will further explore the potential clinical application of Art as a chemotherapeutic drug for esophageal cancer.

\section{Acknowledgements}

This study was supported by a grant from The Hebei Province Medical Scientific Research Key Project (no. ZL20140126).

\section{References}

1. He SP, Tan GY, Li G, et al: Development of a sensitive monoclonal antibody-based enzyme-linked immunosorbent assay for the antimalaria active ingredient artemisinin in the Chinese herb Artemisia annua L. Anal Bioanal Chem 393: 1297-1303, 2009.

2. Tanaka H, Putalun W, De-Eknamkul W, Matangkasombut O and Shoyama Y: Preparation of a novel monoclonal antibody against the antimalarial drugs, artemisinin and Art. Planta Med 73: 1127-1132, 2007.

3. Harris P, Price S, Senthuran S, Cochupanachimootil J and Norton R: Automated erythrocytapheresis for severe falciparum malaria. Intern Med J 41: 60-63, 2011.

4. McLean WG and Ward SA: In vitro neurotoxicity of artemisinin derivatives. Med Trop (Mars) 58 (Suppl 3): 28-31, 1998.

5. Efferth T, Dunstan H, Sauerbrey A, Miyachi $H$ and Chitambar CR: The anti-malarial Art is also active against cancer. Int J Oncol 18: 767-773, 2001.

6. Hamacher-Brady A, Stein HA, Turschner S, et al: Art activates mitochondrial apoptosis in breast cancer cells via iron-catalyzed lysosomal reactive oxygen species production. J Biol Chem 286: 6587-6601, 2011.

7. Blomberg I and Hoffmann I: Ectopic expression of Cdc25A accelerates the $\mathrm{G}(1) / \mathrm{S}$ transition and leads to premature activation of cyclin E- and cyclin A-dependent kinases. Mol Cell Biol 19: 6183-6194, 1999.

8. Chen MS, Ryan CE and Piwnica-Worms H: Chk1 kinase negatively regulates mitotic function of $\mathrm{Cdc} 25 \mathrm{~A}$ phosphatase through 14-3-3 binding. Mol Cell Biol 23: 7488-7497, 2003.

9. Galaktionov K, Lee AK, Eckstein J, et al: CDC25 phosphatases as potential human oncogenes. Science 269: 1575-1577, 1995.
10. Mailand N, Podtelejnikov AV, Groth A, Mann M, Bartek J and Lukas J: Regulation of $\mathrm{G}$ (2)/M events by Cdc25A through phosphorylation-dependent modulation of its stability. EMBO J 21: 5911-5920, 2002.

11. Falck J, Mailand N, Syljuasen RG, Bartek J and Lukas J: The ATM-Chk2-Cdc25A checkpoint pathway guards against radioresistant DNA synthesis. Nature 410: 842-847, 2001.

12. Mailand N, Falck J, Lukas C, et al: Rapid destruction of human Cdc25A in response to DNA damage. Science 288: 1425-1429, 2000.

13. Molinari M, Mercurio C, Dominguez J, Goubin F and Draetta GF: Human Cdc25 A inactivation in response to $S$ phase inhibition and its role in preventing premature mitosis. EMBO Rep 1: 71-79, 2000.

14. Gasparotto D, Maestro R, Piccinin S, et al: Overexpression of CDC25A and CDC25B in head and neck cancers. Cancer Res 57: 2366-2368, 1997.

15. Dixon D, Moyana T and King MJ: Elevated expression of the cdc25A protein phosphatase in colon cancer. Exp Cell Res 240: 236-243, 1998.

16. Nishioka K, Doki Y, Shiozaki H, et al: Clinical significance of CDC25A and CDC25B expression in squamous cell carcinomas of the oesophagus. Br J Cancer 85: 412-421, 2001.

17. Wu W, Fan YH, Kemp BL, Walsh G and Mao L: Overexpression of cdc25A and cdc25B is frequent in primary non-small cell lung cancer but is not associated with overexpression of c-myc. Cancer Res 58: 4082-4085, 1998.

18. Siddiqui WA, Ahad A and Ahsan H: The mystery of BCL2 family: Bcl-2 proteins and apoptosis: An update. Arch Toxicol 89: 289-317, 2015.

19. Shi LS, Wang H, Wang F, et al: Effects of gastrokine-2 expression on gastric cancer cell apoptosis by activation of extrinsic apoptotic pathways. Mol Med Rep 10: 2898-2904, 2014.

20. Gamliel Z: Incidence, epidemiology and etiology of esophageal cancer. Chest Surg Clin N Am 10: 441-450, 2000.

21. Danis $M$ and Jauréguiberry $S$ : The artemisinin derivatives must be in France the first-line treatment of all P. falciparum malaria cases simple or severe. La Prat 63: 896-898, 2013 (In French).

22. Kumnuan R, Pattaradilokrat S, Chumpolbanchorn K, et al: In vivo transmission blocking activities of Art on the avian malaria parasite Plasmodium gallinaceum. Vet Parasitol 197: 447-454, 2013.

23. Shanks GD: For severe malaria, Art is the answer. Lancet 376: 1621-1622, 2010.

24. Okebe J and Eisenhut M: Pre-referral rectal Art for severe malaria. Cochrane Database Syst Rev 5: CD009964, 2014.

25. Steinbruck L,Pereira G and Efferth T: Effects of Art on cytokinesis and $\mathrm{G}(2) / \mathrm{M}$ cell cycle progression of tumour cells and budding yeast. Cancer Genomics Proteomics 7: 337-346, 2010.

26. Yang H, Tian ST, Wu RY, et al: Glycoborinine induces apoptosis through mitochondrial pathway in HepG2 cells. J Asian Nat Prod Res 16: 991-999, 2014.

27. Wimardhani YS, Suniarti DF, Freisleben HJ, Wanandi SI, Siregar NC and Ikeda MA: Chitosan exerts anticancer activity through induction of apoptosis and cell cycle arrest in oral cancer cells. J Oral Sci 56: 119-126, 2014.

28. Zhou X, Sun WJ, Wang WM, et al: Art inhibits the growth of gastric cancer cells through the mechanism of promoting oncosis both in vitro and in vivo. Anticancer Drugs 24: 920-927, 2013.

29. Oh KJ, Barbuto S, Pitter K, Morash J, Walensky LD and Korsmeyer SJ: A membrane-targeted BID BCL-2 homology 3 peptide is sufficient for high potency activation of BAX in vitro. $\mathrm{J}$ Biol Chem 281: 36999-37008, 2006.

30. Viry E, Anwar A, Kirsch G, Jacob C, Diederich M and Bagrel D: Antiproliferative effect of natural tetrasulfides in human breast cancer cells is mediated through the inhibition of the cell division cycle 25 phosphatases. Int J Oncol 38: 1103-1111, 2011.

31. Young LM and Pagano M: Cdc25 phosphatases: differential regulation by ubiquitin-mediated proteolysis. Cell Cycle 9: 4613-4614, 2010.

32. Sengupta $S$, Jana $S$ and Bhattacharyya A: TGF- $\beta-S m a d 2$ dependent activation of CDC 25A plays an important role in cell proliferation through NFAT activation in metastatic breast cancer cells. Cell Signal 26: 240-252, 2014. 